\title{
Meditaciones sobre lo humano en lo animal. Ali, der Schimmelhengst, el autorretrato equino de Alfred Kubin
}

\author{
Rocío Sola Jiménez \\ Universidad Pompeu Fabra \\ rocio.sola@upf.edu
}

RESUMEN: El Expresionismo alemán se caracterizó, entre otros muchos aspectos, por la introducción de lo espiritual y del concepto de empatía dentro de la práctica artística. Con el paso de los años, estas ideas se extendieron más allá del ámbito estético, aplicándose a la percepción de la naturaleza y del reino animal. El artista austriaco Alfred Kubin, uno de los fundadores del grupo El Jinete Azul, continuará la estela que dejó el colectivo tras su disolución en 1914. Casi dos décadas después, Kubin retomó el ideario expresionista en una de sus obras más curiosas: Ali, der Schimmelhengst, una pequeña narración escrita e ilustrada por él donde, a través de la mirada del caballo blanco, cuestiona lo trascendente de la existencia, el destino y la naturaleza de la condición humana.

PALABRAS CLAVE: Alfred Kubin; Animal; Caballo; Condición Humana; Portfolio; Litografía.

\section{Deliberations on the Human and the Animal within. Ali, der Schimmelhengst, Alfred Kubin's Equine Self-Portrait}

ABSTRACT: Two of the aspects that particularly characterise German Expressionism are the spiritual in art and the concept of empathy in the artistic practice. These ideas reached further over the years, also applying them to the perception of nature and the perception of the animal kingdom. The Austrian artist Alfred Kubin, one of the founding members of The Blue Rider group, followed in the wake of this artistic association even after its dissolution in 1914. After almost two decades, Kubin revived the expressionist ideology in one of his most peculiar works: Ali, der Schimmelhengst - a short illustrated tale which questions the transcendental, destiny and nature through the eyes of a white horse.

KEYWORDS: Alfred Kubin; Animal; Horse; Human Condition; Portfolio; Lithography.

Recibido: 28 de febrero de 2019 / Aceptado: 9 de julio de 2019.

La problemática a la hora de discernir en lo referente a lo humano y lo animal es una cuestión que viene de largo. Las teorías y posicionamientos que más eco han tenido al respecto son, quizás, las de Martin Heidegger, Jacques Derrida o, yendo atrás, hacia los inicios de estas cavilaciones, las de René Descartes. Por lo general, el ser humano ha categorizado a los animales a lo largo de la historia del pensamiento dentro de un grupo abstracto que no repara en las particularidades de las especies y que, igual que ocurría con la idea decimonónica de naturaleza, tiene un carácter marcadamente idealizado y óntico. Esta consideración está realizada desde la presunción de superioridad de aquello «propio de lo humano» en comparación con «lo animal». No obstante, pocos han sido los que se han atrevido a intentar delimitar realmente la frontera, o a encontrar algo que le sea único y propio al ser humano.

Lo primero que nos podría venir a la mente al respecto es, como a Walter Benjamin, la ausencia de palabra y de lenguaje que impera en la categoría animal (Hansen, 2000: 161). No obstante, habría que subrayar la existencia de una capacidad dentro de la naturaleza de establecer nexos comunicativos entre todas las criaturas, así como de formar sistemas entre ellos. Es el "sentido humano» de la palabra lo que también determina estas relaciones entre otros seres. En otras palabras, el ser humano, a través de su "capacidad de nombrar» (Benjamin, 1971: 150), de otorgar nombres a las cosas y a los dife-

Cómo citar este artículo: SOLA JIMÉNEZ, Rocío, «Meditaciones sobre lo humano en lo animal. Ali, der Schimmelhengst, el autorretrato equino de Alfred Kubin», Boletín de Arte-UMA, n. ${ }^{4}$ 40, Departamento de Historia del Arte, Universidad de Málaga, 2019, pp. 207-217, ISSN: 0211-8483, e-ISSN: 2695-415X, DOI: http://dx.doi.org/10.24310/ BoLArte.2019.v0i40.5663 
rentes procesos naturales que percibe, puede percatarse de que, efectivamente, la naturaleza se comunica. Walter Benjamin hablaría de este proceso como si de una «traducción de los idiomas menores» se tratase, aunque Jaques Derrida deja claro que el lenguaje y los procedimientos de la naturaleza no son inferiores a los humanos, sino distintos, y estos humanos se encuentran en un constante «deseo de idioma» o «deseo de leer otros textos», refiriéndose con «texto» a las estructuras sociales y a las relaciones que se establecen entre los distintos animales (González, 2017: 305).

Cuanto más se observa a este "otro", más nos damos cuenta de la posibilidad de establecer paralelismos entre sus acciones y las nuestras, al punto que «solo el hombre puede hacer animaladas o bestialidades, puesto que los hechos calificados así no hay forma de atribuírselos a los animales sin incurrir en un claro antropomorfismo» (González, 2017: 302). Dicho esto, la frontera entre el hombre y el animal vuelve a diluirse en un mar de interrogantes.

Otro de los aspectos que se han señalado históricamente como algo inherente y propio al ser humano, y no tanto así a los animales, es el sentido de tiempo. El tiempo humano viene dado por la capacidad de evocar, de recuerdo, de Mnemosyne, que va ligado estrechamente a los sentimientos de anhelo, de nostalgia y de melancolía. La manera orgánica en la que se percibe el tiempo en la naturaleza, en sentido de evolución, desarrollo y deterioro, contrasta con los múltiples planos temporales que los seres humanos son capaces de experimentar de manera inmaterial, siendo para ellos el más incierto de todos el así denominado «presente». Esta idea de ausencia de tiempo aparece también vinculada a los relatos apocalípticos (Larangé, 2009: 149), en los que, además, los animales suelen aparecer, casi de manera sintomática, como señales que vaticinan el fin del mundo que conocemos y el comienzo del que está aún por venir.

Esta idea de revelación, violenta a la par que cargada de espiritualidad, encontró en el movimiento expresionista alemán, más concretamente en las obras del grupo muniqués El Jinete Azul (Der Blaue Reiter), su más excelsa materialización. La Naturaleza se mantiene a lo largo de este movimiento artístico como un espacio iluminador e identitario que se iba desdibujando, imaginando, venerando y meditando a partir de los procesos de abstracción de lo visual y de percepción a través de la empatía. Abstracción y empatía desempeñaban un grado diferente de evocación, de transfi- guración del mundo a partir de la obra de arte, de modo que la categoría de lo estético se convertía en el terreno mediador entre las dos realidades: la del artista y la de la naturaleza que este observa.

Franz Marc (1880-1916) fue uno de los máximos exponentes y fundadores del grupo Jinete Azul, junto a Wassily Kandinsky, Gabriele Münter, August Macke, Alexej von Jawlensky y Alfred Kubin. Marc estuvo fuertemente influenciado por la obra de Wilhelm Worringer Abstracción y empatía (Abstraktion und Einfühlung), una teoría que venía fraguándose de largo y que podía rastrearse desde las divagaciones estéticas alemanas del Sturm und Drang con Wilhelm Wackenroder. Las teorías de la contemplación de lo bello de Arthur Schopenhauer también están vinculadas a esta manera de percibir la naturaleza desde una perspectiva meramente estética y pasiva, con tal de buscar en la contemplación una suerte de trascendencia que le es propia tanto a la naturaleza como al ser humano en sí, y por tanto, también le sería propia al objeto que aparece en la intersección de ambas realidades: la obra de arte.

Para Franz Marc, la simpatía estética significaba también experimentarse y reconocerse en «lo otro», al tiempo que esta característica que observamos se intensifica en nosotros mismos, acercándonos así a la naturaleza y a las realidades que vemos representadas (Morgan, 1996: 321-322). Así pues, en sus pinturas encontramos plasmado el ritmo orgánico de todas las cosas, en los animales, en los árboles, en el aire y en el flujo vibrante de la naturaleza en un intento de escapar de las apropiaciones antropomórficas que el ser humano procuraba a partir de su acercamiento curioso y hermenéutico. En su etapa creativa temprana estableció una crítica a ese «único ojo» de lo humano que mira por todas las criaturas conocidas (Morgan, 1996: 329) y que destruye la imagen de la naturaleza.

Esta idea de la destrucción del medio y del entorno animal mediante la presencia de lo humano irá derivando con el paso de los años hacia una disolución de la frontera idealizada que en un primer momento él mismo había construido. Ahora las formas iban tornando poco a poco en máscaras, tras las cuales el espíritu ha dejado de actuar. El arte, según se van acercando los funestos años de la Primera Guerra Mundial, irá poco a poco cambiando sus ropajes de mediador con lo trascendente hacia un plano de encuentro con «el otro» e incluso con el artificioso reino que Paul Celan 
referirá como «el punto de unión en el que convergen tanto el mono como el autómata» (Hansen, 2000: 156). Es aquí donde se materializan los peligros de ir «más allá de lo humano», dando lugar a lo extraño, a la desfamiliarización de las formas, en otras palabras: a lo fantástico.

La frontera entre lo animal y lo humano experimenta un marcado proceso de disolución en el terreno de lo fantástico. Aludiendo a las máscaras anteriormente mencionadas, podemos advertir cómo, efectivamente, a lo largo de las representaciones de animales en el arte (y de manera mucho más notoria a lo largo de las vanguardias) se les ha otorgado a estos una serie de características y de atributos que corresponden a lo humano y viceversa, comenzando con un proceso de transformación y metamorfosis cuyo resultado torna en lo monstruoso y lo quimérico.

Llegados a este punto, es imprescindible traer a colación al «organizador de lo desconocido, de lo híbrido, de lo crepuscular y de lo onírico»" (Klein, 1983: 10), al más olvidado de los miembros fundadores del Jinete Azul: el dibujante austriaco Alfred Kubin (1877-1959).

La vida de Alfred Kubin abarca algo más de la primera mitad del siglo $X X$, época marcada por hitos que han moldeado el mundo y la sociedad occidental tal y como los conocemos hoy día. Durante las primeras décadas de la centuria desfilaron y se entrelazaron múltiples tendencias artísticas que componen el gran mosaico de las Vanguardias, así como se van dibujando algunas problemáticas filosóficas que abrirán las puertas de lo que entendemos por Posmodernidad. Alfred Kubin habita, en este sentido, un espacio doble. Si bien estuvo vinculado personal y profesionalmente a los mayores cambios sociales, artísticos, literarios y filosóficos que se fraguaron en el terreno convulso que era la Alemania de entonces, no hay que olvidar que, gran parte de esta implicación y de su reflexión al respecto la realizó en una especie de autoexilio, en la sombría seguridad de su morada, el «Schloß» de Zwickledt am Inn.

La formación de Kubin parte de una amplia y curiosa aproximación a las diferentes técnicas artísticas. El interés por el dibujo ya venía mostrándose desde la infancia, aunque su primera toma de contacto con el mundo de lo artístico tendría lugar en el taller fotográfico de su tío Alois Beer. A esto le sucedió un breve periodo en la Academia de Bellas Artes de Múnich (Münchener Akademie der Bildende Künste) a cargo de Nikolaus Gysis que, al igual que ocurrió con otros estudios de formación, no llegó a finalizar. A partir de aquí, espoleada su imaginación por las continuas visitas a los museos de la capital bávara, así como por las veladas en los bares del distrito bohemio, fue dando forma a sus primeros dibujos, fruto de un inquieto mundo interior que se enriquecía día a día a partir del círculo de amistades y de influencias que aquel entorno le brindaba. En este sentido cabe destacar su amistad con los escritores Thomas Mann y Herman Hesse, o con artistas de la talla de Kandisnky y Franz Marc, junto a quienes además expondría en varias ocasiones antes de consolidar el grupo El Jinete Azul.

No obstante, la naturaleza introspectiva de Kubin, junto a una serie de circunstancias personales y familiares, le hicieron decidirse en 1906 a comprar un antiguo castillo del siglo XVI en la frontera de Austria y Alemania, cerca de Schärding, donde permanecería junto a su esposa, su criada y una variada multitud de animales hasta su muerte en 1959. Este estado de semi-exilio no le eximió de ser partícipe del panorama de actualidad artística (fueron varios los viajes que contaba a sus espaldas, llegando incluso a viajar a París para conocer a Picasso), aunque su relación con esa realidad «al otro lado" se llevó a cabo a partir de una corriente continua de cartas y postales que hablan del proceso creativo y de la búsqueda interior en la que, día tras día, se embarcaba Kubin a bordo de aquél espacio que pasó a denominar como «su Arca».

En cuanto a las fases estilísticas, encontramos diferentes propuestas dependiendo del autor que consultemos. Lo más común es encontrar una división desigual cuya fecha de impasse es 1909, año de publicación de su primera y única novela ilustrada La otra parte (Die andere Seite) (Brockhaus, 1977; Hoberg, 1991; y Geyer, 1995). No obstante, para el tema que nos concierne, es la división de Peter Assmann (1998: 23-25) la que mejor se ajusta a los cambios ya no tanto estilísticos sino de contenido, en relación a la percepción del entorno y a la reflexión sobre la condición animal y humana en las obras de Kubin.

La postura de Assmann parte de la concepción de la obra de Kubin como un bestiario «a la medieval», en el que diferentes mundos de corte onírico se entrelazan entre sí: mundos habitados por criaturas de todo tipo que muestran aspectos «facetados» de la realidad (1998: 21). Cuando uno lee acerca de la obra de Alfred Kubin, lo más normal es encontrar descripciones que nos hablan de un ejercicio 


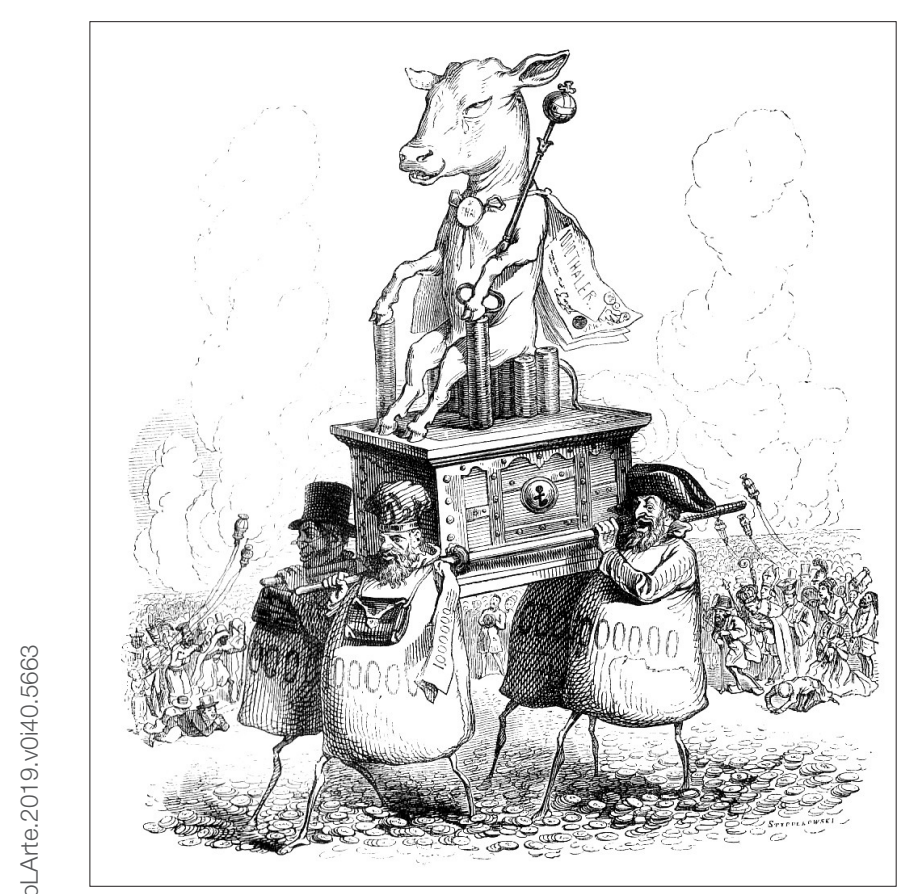

1. Jean Jacques Grandville, El Becerro de Oro, ilustración para Un Autre Monde, 1844

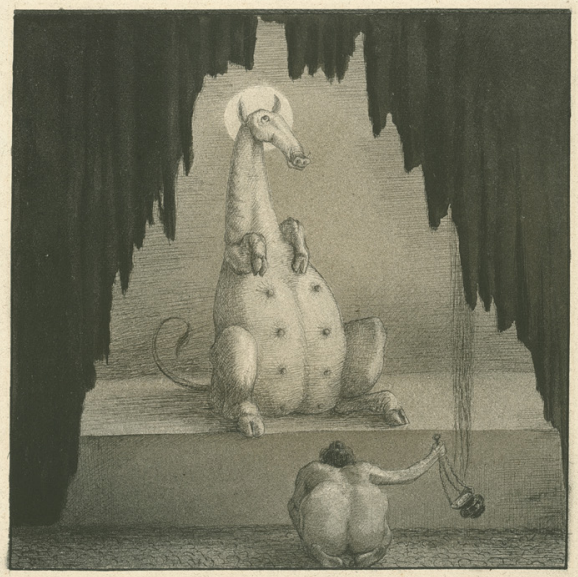

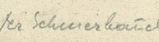

2. Alfred Kubin, Adoración (la barriga), 1900/1901 (Inv. Ha. II 3161 Landesgalerie Linz, Graphische Sammllung). (c) Eberhard Spangenberg/VEGAP, 2019 de interioridad que tiene lugar en un espacio atemporal con guiños a un pasado en el que el autor coloca sus introspecciones ontológicas, recuperando, en muchas ocasiones, formatos como el del bestiario. El ser humano, en estas obras, suele revelarse como una degeneración de determinados aspectos que se observan en el mundo animal, precipitándose dentro de la categoría de lo monstruoso, al tiempo que la imagen del animal se convierte en una quimera debido a su «humanización» (Larangé, 2009: 142). El concepto de lo monstruoso a partir de la humanización de lo animal nos transporta directamente al clima de la Revolución Industrial, tras la cual, las ciudades y la idea de masa comienza a delinearse como la némesis de la naturaleza, extendiendo sus tentáculos por los espacios agrestes, ajenos a la presencia del hombre, dando así lugar a toda suerte de «animales urbanos». Esta crítica a la sociedad decimonónica a partir del énfasis en los rasgos animales dentro de las pautas de comportamiento social puede apreciarse perfectamente en los dibujos de Jean-Jacques Grandville [1] y [2], muy admirado por Kubin y, sin duda, una de sus mayores influencias. El bestiario kubiniano, por tanto, no se limita a indexar una serie de taxonomía de especies y de monstruos, sino que se dedica a describir la poética que subyace tras esas especies quiméricas que se organizan bajo una percepción desprovista de espiritualidad que para Kubin es la del hombre moderno.

Atendiendo a esto, Peter Assmann encuentra tres momentos fundamentales en la obra de Alfred Kubin a la hora de analizar el bestiario de su obra. En primer lugar, el periodo que va de 1898 a 1904, el «Frühwerk», se correspondería con la presentación de todas las diversas formas que surgirán y se desarrollarán como un continuo en los dibujos, a saber: representaciones de una fauna orientada casi siempre a seres presentes en la naturaleza, imágenes del animal como un dios al que rendir culto y practicar ofrendas, escenas de persecución y lucha de contrarios, etc. (Assmann, 1998: 23). Esto coincide con la división que haría previamente Peter Brockhaus, que además de los temas citados señala la antítesis del animal considerado como dios con su némesis el «Tierphantom», así como las figuras híbridas entre animal y ser humano (1974: 286).

La segunda etapa recogida por Assmann, entre 1904 y 1909, presenta dos vertientes. Por un lado, destaca la influencia que sobre Kubin ejerció Koloman Moser a partir de las obras de 1906, centradas sobre todo en imaginar criatu- 
ras subacuáticas imposibles que cobraban vida a partir de una técnica efectista de témpera, engrudo y parafina. Por otro lado, nos encontramos en la fase preparatoria de la novela La otra parte, en la que tienen cabida bajo el mismo paraguas los bosquejos filosóficos del artista junto con algunos recuerdos de su infancia y de su vida en general, donde los animales cobraban un valor fundamental.

En el proceso de ilustración de la novela se prefigura el simbolismo de revelación violenta que se le otorga a lo animal dentro de la obra kubiniana del periodo que va de 1920 a 1940 (1998: 25). Durante estas dos décadas tiene lugar una consolidación del estilo, que ya había comenzado a virar a partir de 1909 de unas figuras que contrastaban suavemente con los espacios crepusculares en los que se movían (difuminados a partir de la aguada de tinta china y el espray), hacia una factura sismográfica, nerviosa, en el que la pluma rasgaba y se enmarañaba en el papel dando lugar a unas composiciones sintomáticas del estado de ánimo del artista. A partir de aquí es muy común encontrarnos con evocaciones y reinterpretaciones de obras pasadas, entre las cuales se escondían imágenes de la infancia y del subconsciente onírico. Esta época también marca una relación mucho más estrecha con el formato del libro infantil ilustrado, encontrando entre los estantes de la biblioteca personal de Kubin en Zwickledt un sinfín de ejemplares de cuentos y leyendas populares, de historias para niños y de fábulas protagonizadas por animales que, sin lugar a dudas, influenciaron la obra que nos concierne en esta reflexión: el cuento ilustrado de 1932 Ali, el semental blanco - Destino de un caballo tártaro en 12 láminas (Ali, der Schimmelhengst - Shicksal eines Tatarenpferdes in 12 Blättern) [3].

Este pequeño portfolio consta de 16 litografías, 12 de las cuales corresponden a las ilustraciones y 3 al texto, dejando una para la portada. Están realizadas a partir de una preparación de papel encerado sobre el que Kubin dibujaba directamente, transfiriendo a posteriori la imagen a las planchas de piedra. A diferencia de otras obras literarias ilustradas por Kubin, aquí se muestra una particularidad, y es que la caja de texto cuenta con la escritura a mano del autor mediante la misma técnica de las ilustraciones, en un estilo que puede traernos a la mente ecos lejanos del proceso de trabajo del gran maestro visionario William Blake. El contenido, no obstante, parece abandonar a primera vista el discurso metafísico en pos de refugiarse en el mundo de las fábulas y

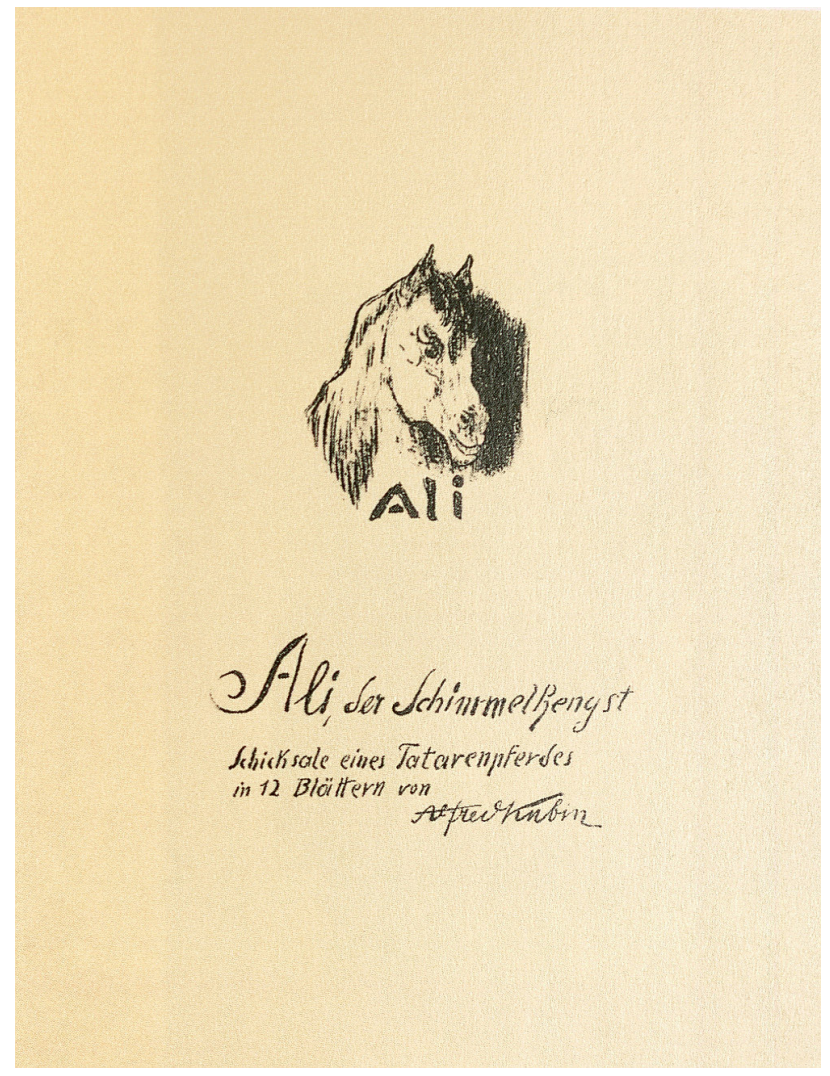

3. Alfred Kubin, Ali, portada, 1932 (Marks A113 / 1350) (C) Eberhard Spangenberg/NEGAP, 2019

de las leyendas, utilizando para ello el recurso de colocar un protagonista animal cuya vida se desarrolla en un país muy lejano y en un tiempo incierto.

Tras una primera lectura, podría parecernos que la obra bebe directamente de las pequeñas narraciones en las que destaca el vínculo entre el jinete y su montura, una imagen que arrastra tras de sí una carga simbólica que se remonta al imaginario de las primeras culturas indoeuropeas, al tiempo que puede encontrarse también en el imaginario cristiano en el que solo se considera como emblema el binomio caballo-jinete, unidos, destacando la imagen de Cristo como Rey vencedor del Mundo a lomos del caballo blanco y su contrario, la muerte que cabalga un caballo pálido (Charbonneau-Lassay, 1997: 212). No obstante, esta imagen del binomio tiene un tinte mucho más trascendental y metafísico según nos aproximamos a las culturas oriundas de la zona en la que Kubin sitúa la acción de su pequeño cuento: Manchuria. 


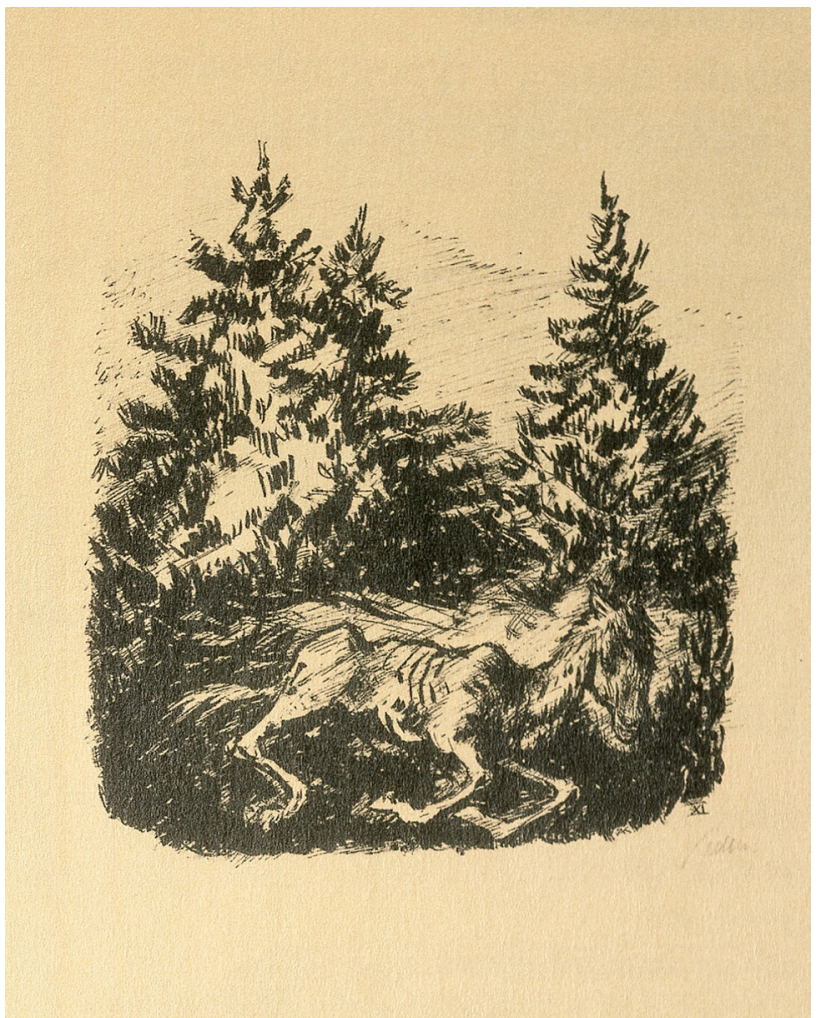

4. Alfred Kubin, XII: Ya ciego, Ali, 1932 (Marks A113 / 1350) (C) Eberhard Spangenberg/VEGAP, 2019

En la biblioteca del «Schloß» de Zwickledt se encuentran numerosos tomos sobre el folklore y las leyendas de los pueblos del Indostán así como de Oriente Próximo, encontrando en ellos una simbología muy particular en lo que respecta a la figura del caballo. La imagen más clara del dios a lomos de un caballo blanco procede del hinduismo y el budismo, y se trata de Kalki, la décima y última reencarnación (o avatara) de Vishnú en los Veda. No obstante, resulta mucho más interesante el ejemplo que recoge Jean Chevalier en su diccionario de símbolos, apelando a uno de los relatos que perfectamente pudieron influenciar decisivamente en el contenido del portfolio Ali, el semental blanco, perteneciente a la mitología de la civilización turco-mongola de los Kirguís. Los pueblos Kirguís recogen la epopeya de Er-Töshtük, un héroe de tinte chamánico que debe bajar al infierno a lomos de un caballo blanco, único animal capaz de conducir al valiente al más allá, y que cumple una función de providencia y de pre-visión que apela a la capacidad que se le suponía al caballo de guiar a su jinete en la oscuridad, allí donde los ojos del hombre son incapaces de ver (Chevalier, 1986: 209). Sin embargo, es curioso cómo aquí Kubin juega precisamente con el mito en el sentido opuesto, siendo el caballo ciego quien, en su último hálito vital, se precipita al abismo animado por las palabras de su jinete, que había devenido en mago [4].

Del mismo modo, la visión del caballo blanco en relación con las aguas (pues son varias las ocasiones en las que se menciona que Ali merodea por los pantanos y gusta de bañarse en el río) puede partir de la tradición literaria decimonónica alemana, concretamente de la novela de 1888 El jinete del caballo blanco (Der Schimmelreiter) de Theodor Storm. La simbología que toma cartas en la construcción de esta novela se pierde en la noche de los tiempos, encontrando múltiples ejemplos de analogías entre el caballo en un entorno acuático y la premonición funesta de la muerte dentro de diferentes construcciones mitológicas galas y anglosajonas, que acabaría derivando en la creencia que imperaba tanto en la Alemania como en la Inglaterra de los siglos XVIII y XIX de que la visión onírica de un caballo blanco era presagio de muerte (Cirlot, 1992: 110), y de donde bebe el archiconocido lienzo de Johan Heinrich Füssli, en el que el caballo, casualmente, también parece ciego [5].

Como ocurre con casi todas las obras de Alfred Kubin, al sustrato simbólico y metafísico se le superpone una capa autobiográfica y personal que desdibuja los mitos y las leyendas en pos de crear un imaginario independiente que gira en torno a la figura «ideal» del artista $^{2}$, y el portfolio Ali, el semental blanco no es una excepción. Para empezar, el propio nombre del caballo protagonista ya sugiere un acróstico del nombre de pila completo del autor: Alfred Leopold Isidor. La elección de este nombre para el animal sugiere una lectura a la inversa de todos los símbolos mencionados anteriormente, dejando entrever al ser humano como el único y verdadero axioma de lo funesto, a la par que como un ente dotado de una visión trascendental (especialmente cuando Kubin pasa a referirse al ser humano como demiurgo, como artista y como creador).

Por lo general, Kubin asocia la imagen del caballo galopante a una de las experiencias que tuvo de niño durante su estancia en Zell am See (Brockhaus, 1974: 294) y que recoge en el compilado de textos Aus meinem Werksatt (Desde mi taller) bajo el título Angst und Bangigkeit (Miedo e 
inquietud). En este pequeño fragmento relata su encuentro con un caballo desbocado que galopaba calle abajo causando un estruendo con el repiqueteo de sus cascos. El niño Kubin buscó refugio a contrarreloj en el umbral de la puerta de una casa, librándose de ser arrollado por el animal. La impresión causada por la fuerza del caballo y el pavor que le causaron sus ojos desorbitados hacen pensar que Ali, el semental blanco pueda ser un esfuerzo literario por controlar esa potencia desbordante de la naturaleza, acoplándole al caballo blanco un jinete-mago, en un intento de resolver la dualidad entre animal y humano mediante la fusión de las dos entidades, de los dos polos, en un solo símbolo.

El episodio del caballo también puede rastrearse en la novela La otra parte, cuando el protagonista, a petición de su esposa, se adentra en el "pozo de fantasmas» que era el sótano de una lechería. En las profundidades, y apelando de nuevo al vínculo que existe entre el más allá y el caballo como símbolo, aparece un caballo blanco con las cuencas de los ojos vacías que pasa por su lado en un frenético galope [6]:

Un viento helado me rozó la cara y al punto distinguí un caballo blanco y esquelético. Aunque solo lograba ver su silueta borrosa, pude advertir el catastrófico estado en el que se hallaba. (...) Y así, con su huesuda cabeza tendida hacia

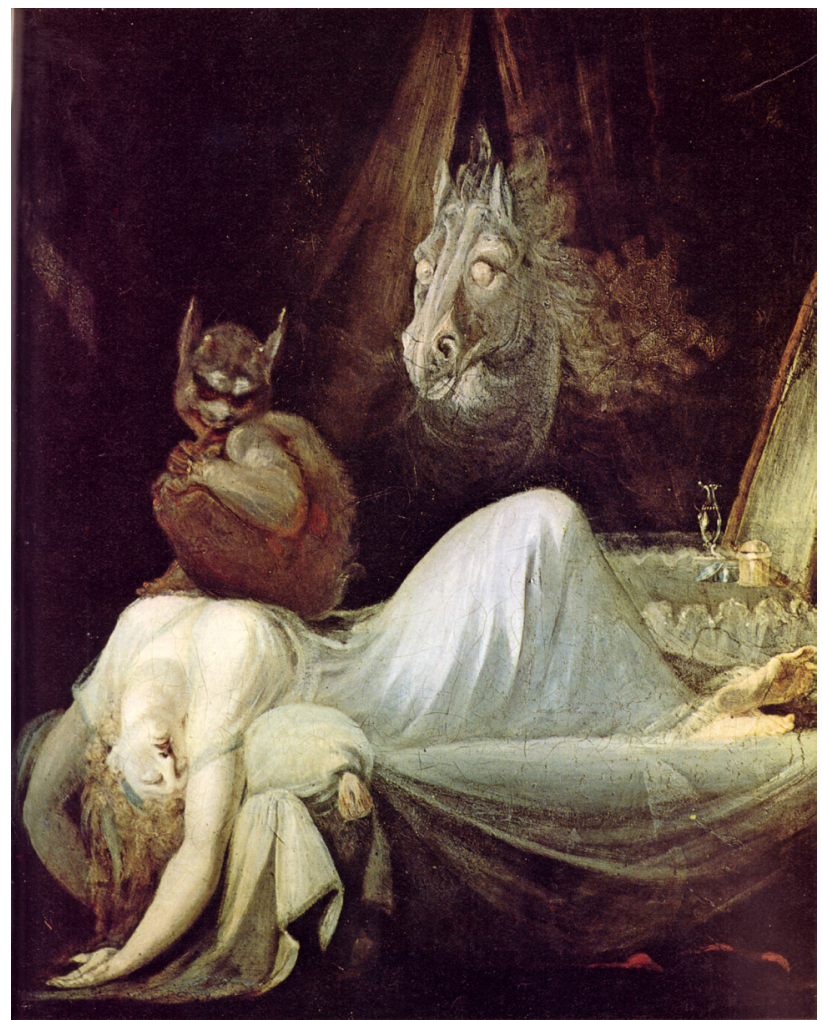

5. Heinrich Füssli, La pesadilla, segunda versión, 1790-1791 (Colección Goethe Haus Frankfurt)
6. Alfred Kubin, El caballo fantasma, ilustración para La otra parte, 1909 (Kub. 349 Kubins Archiv im Lenbachhaus, Múnich) (C) Eberhard Spangenberg/VEGAP, 2019

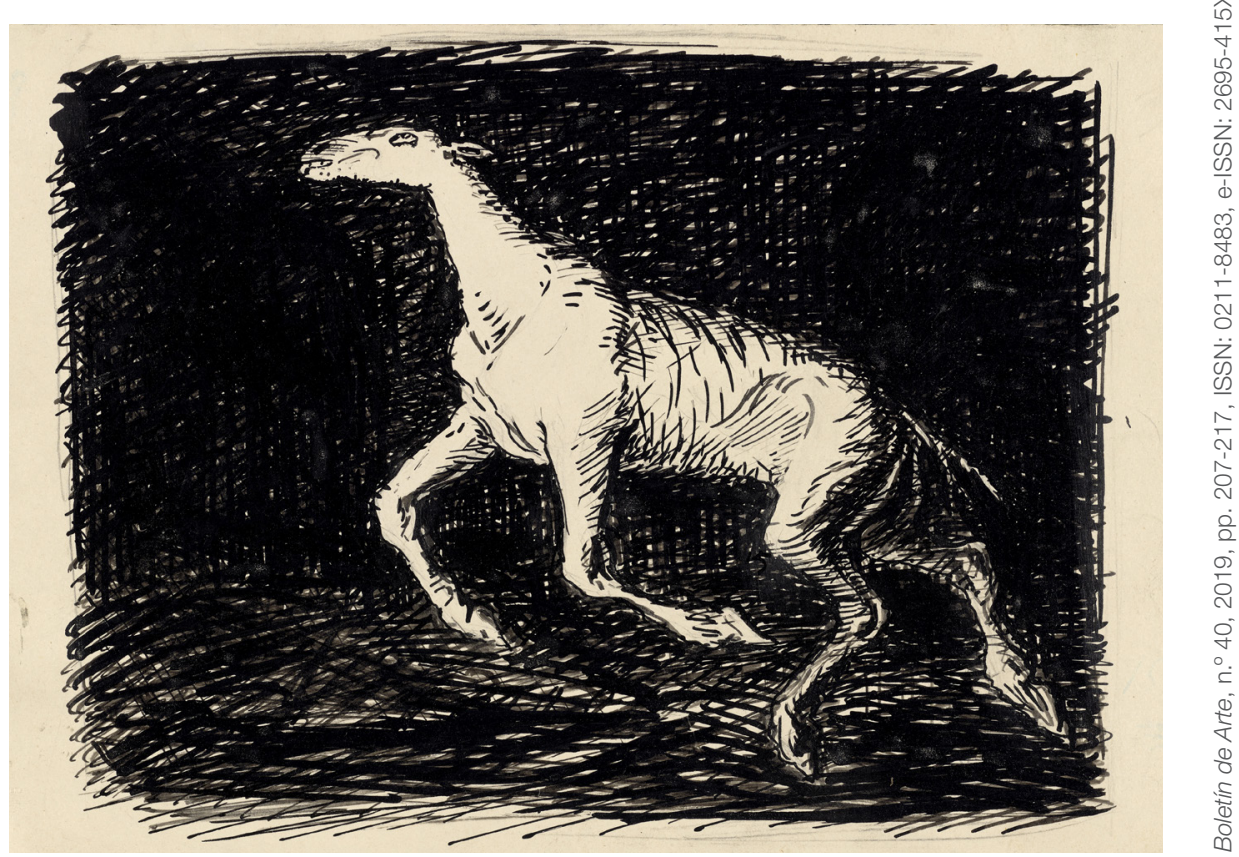




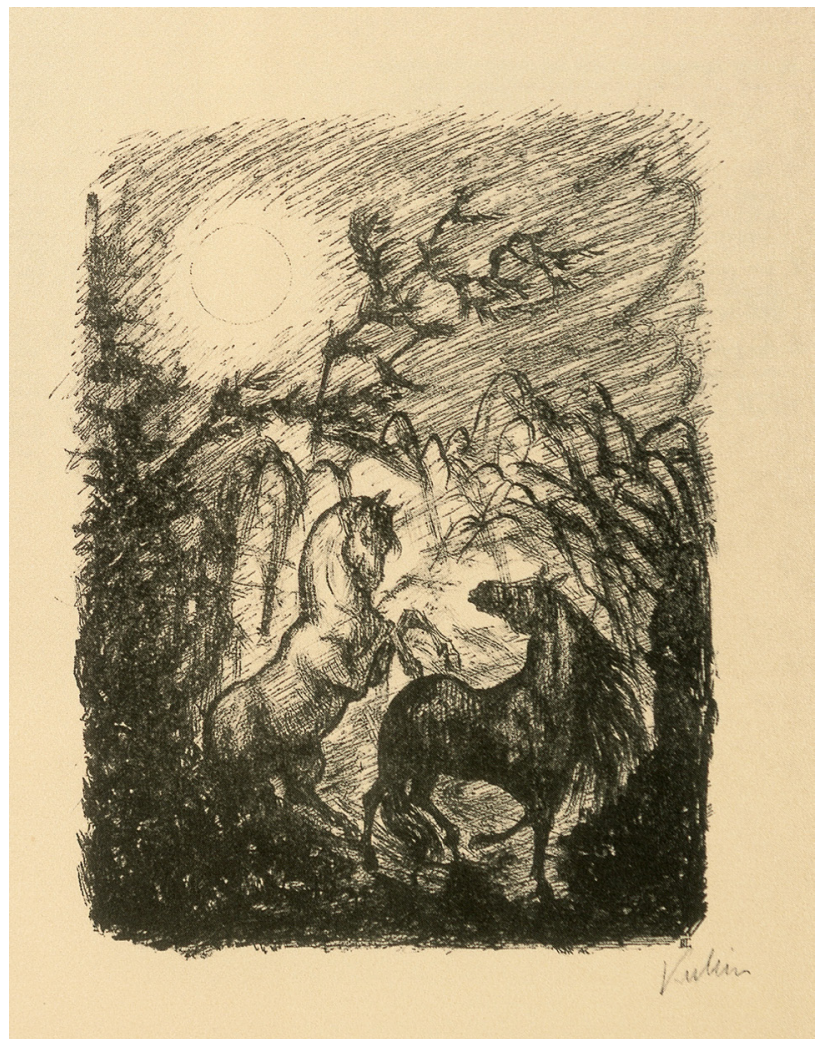

7. Alfred Kubin, III: Más tarde, encontró una joven yegua, 1932 (Marks A113 / 1341) @ Eberhard Spangenberg/VEGAP, 2019

adelante y las orejas caídas, la bestia pasó por mi lado. Su ojo turbio y sin brillo se cruzó con los míos: era ciego (Kubin, 1974: 97-98).

La relación entre la mirada vacía de este caballo con la de Ali al final de su vida resulta bastante evidente, así como la relación dentro de la novela entre esta mirada blanca y la que Kubin le atribuye al jerarca del Reino de los Sueños en el que transcurre la trama. Los ojos en la obra de Kubin se convierten en un motivo recurrente, muy en consonancia con las pinturas de Odilon Redon. Aquí, el ojo se convierte en un abismo que nos devuelve la mirada, que nos devuelve al horror de la escena a través de las cuencas vacías, como una especie de alegoría de la muerte en vida. Es por esto que cabe reseñar también el paralelismo entre Ali, que vive su infancia «bajo los ojos de su madre» (Kubin, 2004: 61) y la infancia de Alfred Kubin, quien perdió muy pronto a la suya. Aquí entra en juego la teoría de Carl Gustav Jung, que ve en

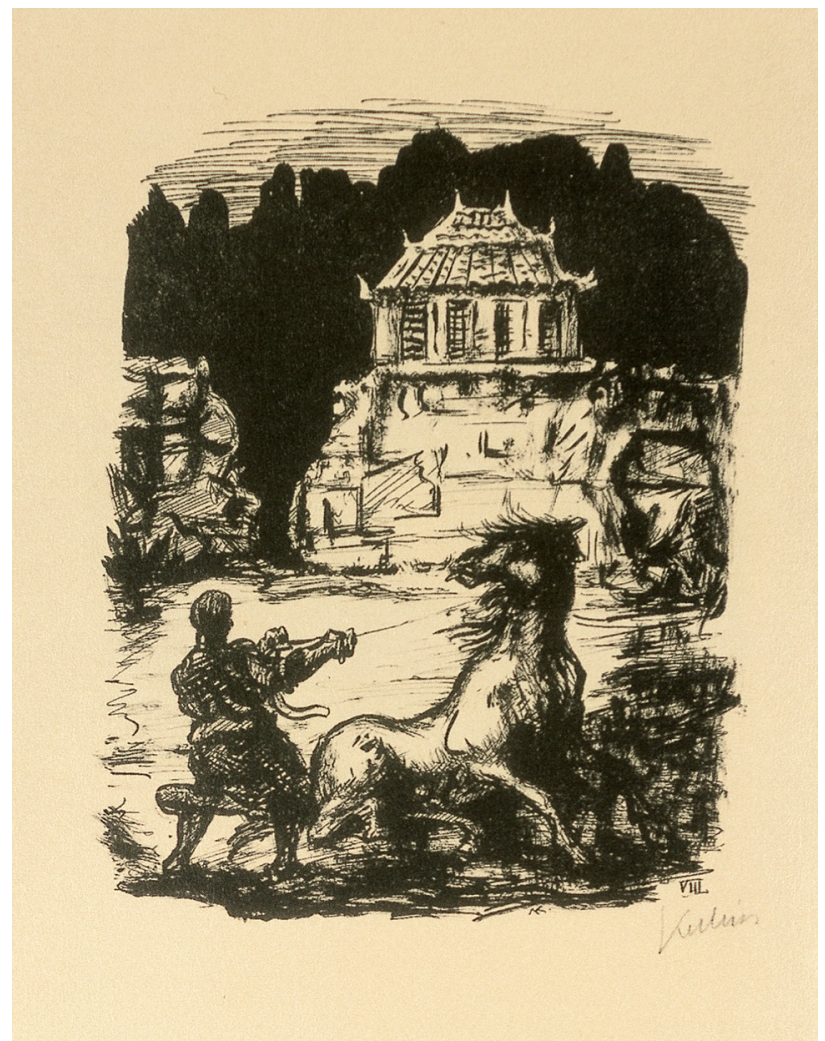

8. Alfred Kubin, VIII: Un hábil domador, 1932 (Marks A113 / 1346) @ Eberhard Spangenberg/NEGAP, 2019

la imagen del caballo el símbolo de «la madre en nosotros» (Cirlot, 1992: 111), lo que coloca a Ali-Kubin como creación vital y como extensión de la figura materna, a raíz la experiencia traumática y descarnada de la muerte tal y como es, algo que predomina como tema central en toda su obra.

Lo femenino también se atisba en el portfolio cuando, en la lámina 3, se nos introduce a una yegua negra de la que no se menciona el nombre [7]. No obstante, la lectura de su autobiografía es bastante reveladora al respecto. A principios del año en que se publica el portfolio, Alfred Kubin conoce a una joven artista que dejará una profunda huella tanto en su corazón como en su imaginario: Emmy Haesele. En las ilustraciones y en la trama de Ali tan solo se menciona el juego y el «galope feliz» bajo la luna, haciendo quizás mención a unos sentimientos reprimidos que posteriormente serían revelados y correspondidos, comenzando así una relación amorosa con Haesele que se llevaría a cabo en dos planos: el real (un secreto a voces) y el imaginario de las cartas, mares de pa- 


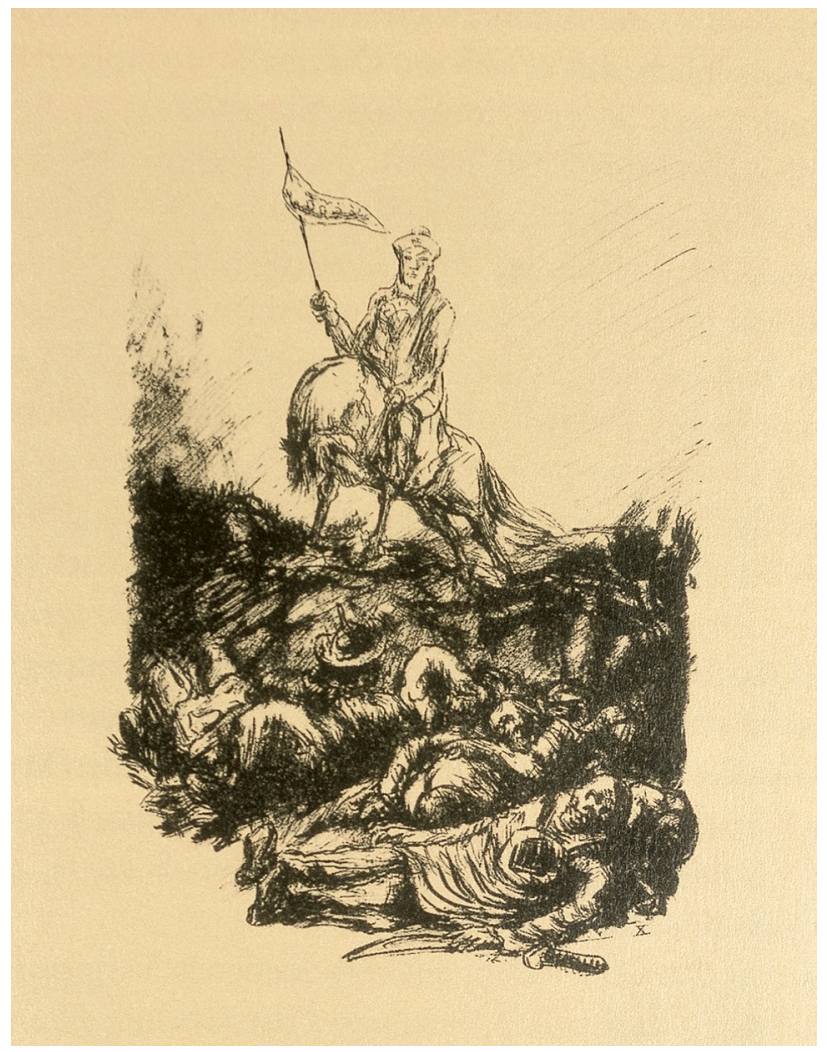

9. Alfred Kubin, X: Un príncipe Manchú, 1932 (Marks A113 / 1348) C Eberhard Spangenberg/VEGAP, 2019

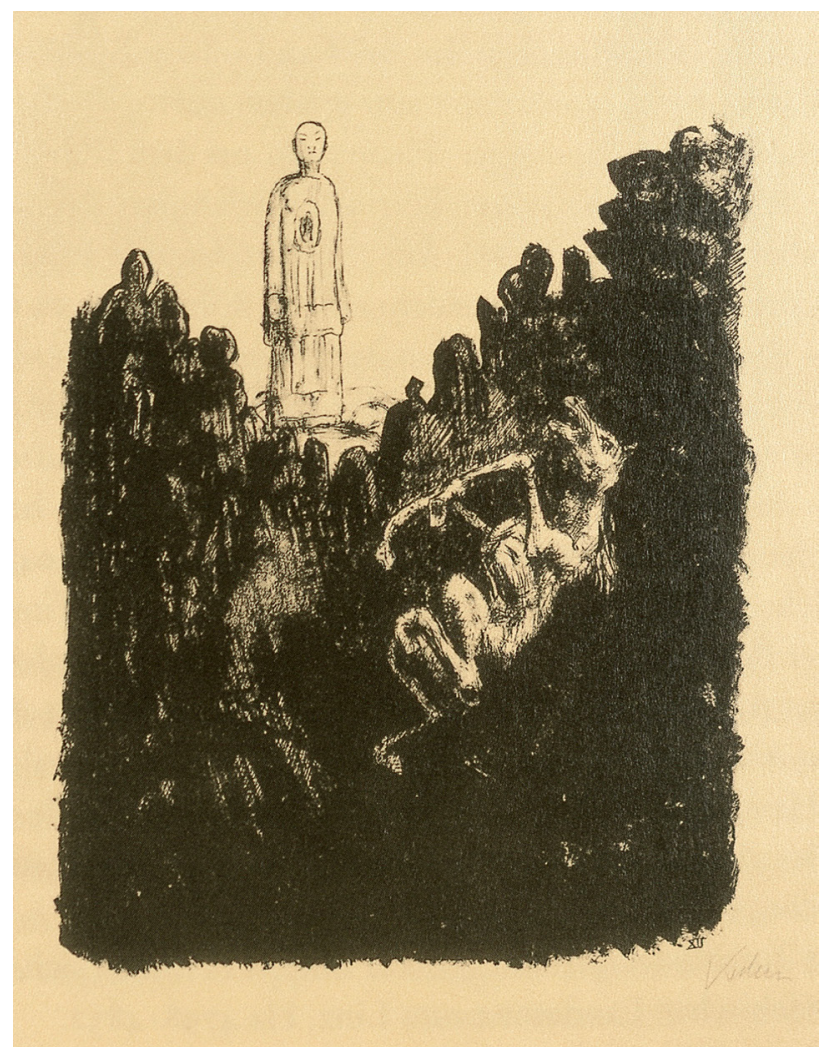

10. Alfred Kubin, XI: Tras la victoria, 1932 (Marks A113 / 1349) (C) Eberhard Spangenberg/VEGAP, 2019 pel en los que tenía lugar la bucólica relación del caballo Ali y la yegua Fatme, una historia paralela y mucho más optimista que la recogida en el portfolio (Wally, 1993: 17).

Pese a esta pulsión sexual oculta tras la imagen del caballo Ali, como bien explica también en sus cartas a Hanne Koeppel (Kubin, 1979: 81-82) sería erróneo concluir que es este el único tema que vehicula la temática y la razón de ser del portfolio, como aparece recogido por Peter Assmann (1998: 25). La temática de lo animal está muy presente en toda la trayectoria de Alfred Kubin, encontrando en ella, como se ha mencionado anteriormente, diferentes variantes. Daniel S. Larangé señala una evolución que parte de la lucha de los contrarios, en este caso de individuo y animal, hasta la fusión de los dos extremos del espectro, dando lugar a las formas quiméricas y monstruosas tan características de los dibujos de Alfred Kubin. Ali mostraría precisamente la idea de la lucha, la contraposición entre ser humano y animal, entendido este como un impulso indoma- ble y oscuro de la naturaleza, que es castigado bajo el látigo y que forcejea contra aquél extraño ser que lo ha sacado de su entorno y le ha impuesto un destino, que no es otro que la batalla y la lucha [8].

Las láminas 10 y 11 del portfolio son dos ejemplos magníficos de esta contraposición. En la lámina 10 [9] nos encontramos al jinete que se eleva sobre un rastro de muertos, donde se alude a la fuerza indómita que es Ali siendo controlada fuera de su entorno. Larangé menciona este fenómeno como «bestialidad desnaturalizada» y «bestialidad cultural» (2009: 145), que enlaza con la concepción de destino fatalista al que está abocada toda creación tanto natural como humana: la muerte. Este destino puede verse como un guiño al romántico retorno a la naturaleza, como se aprecia en la siguiente lámina [10], en la que Ali yace moribundo enmarcado por el perfil sombrío de los árboles. No se nos muestra tanto como un anhelo a lo anterior, a la libertad del bosque, sino más bien como una vuelta completa en la rue- 
da de la vida, que nos lleva de nuevo a una situación muy similar a la que nos encontrábamos en nuestros inicios. En palabras del propio Kubin, la entrada y la salida de la vida se coloca siempre la misma máscara (Kubin, 2017: 278).

Lo que lleva a preguntarnos por la disolución de fronteras entre lo animal y lo humano al respecto de esta obra es precisamente la elección de Kubin de colocarse a sí mismo en la piel del animal, en cuestionarse la libertad, la clarividencia y la opresión de los constructos culturales no como acostumbraba siempre, desde la mirada del observador que filosofa y especula, sino desde su encarnación en forma de caballo blanco que, lejos de lo que ocurre con los animales de las fábulas, muestra poca señas de «humanidad». La elección del animal tampoco es baladí, pues recoge sus experiencias y pesadillas personales a la vez que trasciende como símbolo de manera transversal en diferentes culturas, convirtiéndolo así en un símbolo tanto privado como universal.

Esta manera de prestar atención a nuestro entorno y a las criaturas que nos rodean es el mejor modo de llegar a lo abierto, a la utopía o a ser realmente libres (Hansen, 2000:
156), entendiendo esa libertad en la obra de Kubin como único medio para vivir y crear, imbricándole así a lo artístico esa cualidad de «tierra de nadie» o de espacio liminar que representa a la perfección el precipicio del final de Ali, el semental blanco.

Lo animal y lo humano, la vida y la muerte, la libertad y la opresión, la civilización y la naturaleza, etc. son presentadas aquí a modo de frontera: una frontera que hay que trascender para llegar donde jamás nadie ha llegado, para así, utilizando de nuevo las palabras de Alfred Kubin, asomarnos al abismo y «tratar de crear allí donde otros hace mucho tiempo cerraron atemorizados los ojos a la pavorosa claridad» (Kubin, 2017: 277-278). La imagen de Ali al borde del abismo y con la visión perdida se convierte, por tanto, en una magistral ilustración de la concepción del destino de la humanidad y del impulso artístico dentro de la filosofía kubiniana, que encuentra, curiosamente, su quintaesencia en la fuerza desbocada y salvaje de lo animal, adelantándose así a su tiempo a la hora de preguntarse por la fina barrera que separa lo uno de lo otro.

\section{Notas}

1 Traducción propia al castellano de un fragmento de una carta de Alfred Kubin a Fritz von Herzmanovsky-Orlando mandada el 9 de enero de 1908: «ich bin der Organisator des Ungewissen, Zwitterhaften, Dämmerigen, Traumartigen».

2 Alfred Kubin contaba con escritos que fabulaban sobre su persona desde 1902, fecha en la que encontramos fragmentos filosóficos y literarios que hablan en tercera persona de un personaje-artista llamado Alfred Kubin y que fabula con la identidad y las capacidades de la persona real, haciendo bastante difícil a posteriori discernir lo real de lo imaginario en sus autobiografías y ensayos.

\section{Bibliografía}

ASSMANN, Peter (2003), «Zum Kult der “Anderen Seite”-Beobachtungen zu Alfred Kubins "Bestiarium”", en IVANOVIĆ, Christine LEHMAN, Jürgen y MAY, Markus, Phantastik - Kult oder Kultur?: Aspeckte eines Phänomens in Kunst, Literatur und Film, Springen Verlag, Berlín-Heidelberg, pp. 57-74.

ASSMANN, Peter y RACHEWILTZ, Siegfried de (1998), Alfred Kubin: Bestiarium. Eine Ausstellung des Landesmuseums Schloß Tirol in Zusammenarbeit mit der Landesgalerie Oberösterreich, Bolzano-Spangerberg, Merano-Múnich.

ASSMANN, Peter y HOBERG, Annegret (1999), Alfred Kubin. Das lithographische Werk, Oberösterreichische Landesgalerie -Hirer Verlag, Linz- Múnich.

BENJAMIN, Walter (1971), «Sobre el lenguaje en general y sobre el lenguaje de los humanos», en Angelus Novus, Edhasa, Barcelona, pp. 145-165.

BONET, Juan Manuel (1998), Alfred Kubin, sueños de un vidente, Conselleria de Cultura, Educació y Ciència de la Generalitat de València. BROCKHAUS, Christoph y PETERS, Hans Albert (1977), Alfred Kubin. Das zeichnerische Frühwerk bis 1904, Kunsthalle Baden-Baden, Baden-Baden. 
CHARBONEAU-LASSAY, Louis (1997), El bestiario de Cristo: el simbolismo animal en la Antigüedad y la Edad Media, Liberduplex, BarceIona, vol. I.

CHEVALIER, Jean (1986), Diccionario de los Símbolos, Herder, Barcelona.

CIRLOT, Eduardo (1992), Diccionario de Símbolos, Labor, Barcelona.

GEYER, Andreas (1995), Alfred Kubin. Träumer auf Lebenszeit. Alfred Kubin als Literat, Böhlau Verlag, Viena -Colonia- Weimar.

GONZÁLEZ GALLINAS, Enrique (2017), «La cuestión del límite entre el hombre y el animal en el pensamiento de Jacques Derrida», ÉNDOXA:

Series filosóficas, n. ${ }^{\circ}$ 40, pp. 291-310.

HANSEN, Beatrice (2000), On Walter Benjamin's other History: of Stones, Animals, Human Beings, and Angels, University of California Press, Berkeley.

HOBERG, Annegret (1991), Alfred Kubin 1877-1959, Städtische Galerie Lenbachhaus, Múnich.

- (2018), Phantastisch! Alfred Kubin und der Blaue Reiter, Lenbachhaus-Wienand, Múnich.

KLEIN, Michael (1983), Fritz von Herzmanovsky-Orlado. Die Briefewechsel mit Alfred Kubin 1903 bis 1952, Residenz Verlag, Salzburgo.

KUBIN, Alfred (1974), Aus meinem Werkstatt: gesammelte Prosa, Nymphenburguer Verlag, Múnich.

- (2017), De mi vida; Desde la mesa del dibujante y otros escritos, Antonio Machado, Madrid.

- (1972). Die wilde Rast. Alfred Kubin im Waldhäuser. Briefe an Reinhardt und Hanne Koeppel, Nymphenburger Verlag, Múnich.

- (2004), El gabinete de curiosidades. Autobiografía, Maldoror, Vigo.

LARANGÉ, Daniel S (2009), «L'animal, l'homme et le monstre dans l'univers onirique d'Alfred Kubin. Du bestiaire à la tératologie humaine», Sociétés \& Représentations, n. ${ }^{\circ} 27, \mathrm{pp} .141-154$.

MARKS, Alfred (1977), Der Illustrator Alfred Kubin: Gesamtkatalog seiner Illusrtationen und buchsküntslerischen Arbeiten, Spangenberg Verlag, Múnich.

MORGAN, David (1996), «The enchantment of Art: Abstraction and Empathy from German Romanticism to Expressionism», Journal of the History of ldeas, vol. 57, n. ${ }^{\circ} 2$, pp. 317-341.

RAABE, Paul (1977), Alfred Kubin 1877-1977, Spangerberg Verlag, Múnich.

WALLY, Barbara (1993), Emmy Haesele, Galerie Altnöder, Salzburgo. 